Original article

\title{
Combined effects of soft drinks and nicotine on Streptococcus mutans metabolic activity and biofilm formation
}

\author{
Lamia S. Mokeem ${ }^{1)}$, Lisa H. Willis ${ }^{1}$, L. Jack Windsor ${ }^{2)}$, N. Blaine Cook $^{1)}$, George Eckert ${ }^{3)}$, and Richard L. Gregory ${ }^{2}$ \\ 'Department of Cariology, Operative Dentistry and Public Health Dentistry, Indiana University School of Dentistry, Indianapolis, IN, USA \\ ${ }^{2)}$ Department of Biomedical Sciences and Comprehensive Care, Indiana University School of Dentistry, Indianapolis, IN, USA \\ ${ }^{3)}$ Department of Biostatistics, Indiana University School of Medicine, Indianapolis, IN, USA
}

\begin{abstract}
The purpose of this study was to explore the effects of nicotine on the activity of Streptococcus mutans (S. mutans) in soft drinks. Regular soft drinks contain large proportions of high-fructose corn syrup (HFCS), which increases the activity of $S$. mutans resulting in high-caries risk compared with sugar-free soft drinks. Nicotine use exhibits a strong correlation with increased $S$. mutans biofilm formation. The soft drinks chosen were (Coca-Cola Classic, Diet Coke, Coca-Cola Zero Sugar, Caffeine-Free Coca-Cola, Caffeine-Free Diet Coke, Caffeine-Free Coca-Cola Zero Sugar). S. mutans was grown overnight in tryptic soy broth; nicotine was diluted in tryptic soy broth supplemented with $1.0 \%$ sucrose followed by soft drinks in dilution of 1:3. Total growth absorbance and biofilm growth were determined by spectrophotometry, absorbance measured to determine biofilm formation, and metabolic activity quantified. One-way ANOVA showed a considerable effect for HFCS and caffeine in the presence of nicotine and their interaction in all measures. Results showed sugar-free caffeinated colas demonstrated significant effect in inhibiting S. mutans biofilm formation and metabolic activity with nicotine. Nicotine-induced $S$. mutans increased biofilm formation and metabolic activity in the presence of HFCS and caffeine in soft drinks. In conclusion, smokers should consider sugar-free caffeinated versions to minimize the chance of developing dental caries dut to the reduction of biofilm formation.
\end{abstract}

Keywords; biofilms, carbonated beverages, fructose, metabolic activity, nicotine, Streptococcus mutans

\section{Introduction}

For decades, dental caries has been one of the most widespread diseases. World Health Organization fact sheets report that dental caries affects $60-90 \%$ of school children and about $100 \%$ of adults around the world (https://www.who.int/news-room/fact-sheets/detail/oral-health, accessed on January 18, 2019). It is known to be a chronic infectious disease that can lead to tooth loss, and is deemed to be a microbial multifactorial disease. The most commonly studied bacterium for dental caries is Streptococcus mutans (S. mutans). It is identified as gram-positive with acidic metabolic products that have strong abilities in changing the etiology of dental plaque [1]. In the US, soft drinks are recognized as the dominant drink among teenagers, and the average consumption is increasing rapidly among the population [2,3]. It has been shown that soft drinks increase caries development and progression as they decrease the $\mathrm{pH}$ through fermentation, leading to lactic acid production [2]. The presence of caries-promoting sugar and high fructose corn syrup (HFCS) in non-diet soft drinks is considered to be one of the most cariogenic factors $[4,5]$.

An important ingredient in many soft drinks is caffeine; it's effect on the cariogenic process should be considered with regards to caffeinated soft drink consumption. It is the most consumed psychoactive substance around the world [6]. Studies demonstrate that caffeine reduces adherence

Correspondence to Dr. Lisa H. Willis, Department of Cariology, Operative Dentistry and Public Health Dentistry, S413 Indiana University School of Dentistry, 1121 W. Michigan St, Inidanapolis, IN 46202, USA

E-mail:1hwillis@iu.edu

J-STAGE Advance Publication: December 14, 2020

doi.org/10.2334/josnusd.20-0073

DN/JST.JSTAGE/josnusd/20-0073 of $S$. mutans to enamel as evidenced in interference with $S$. mutans adsorption to saliva-coated hydroxyapatite beads [7]; but another indicates that it has no cariogenic effects [8]. In 2017, a study was carried out to evaluate the effects of the most prominent components of soft drinks, HFCS and caffeine [9]. The fermentable carbohydrate (HFCS) was found to boost biofilm formation and metabolic activity, which may increase caries activity in teeth. On the other hand, the effect of caffeine on biofilm formation and metabolic activity was not as obvious and less significant compared with the effect of HFCS [9]. Preliminary unpublished data from the study by DuBois and Gregory supports the inhibitory effect of caffeine on S. mutans, and this effect must be taken into consideration when studying $S$. mutans activation factors. Additionally, another potential causative factor in dental caries is smoking. The Centers for Disease and Control (CDC) reports indicate in the US around 42.1 million adults are smokers. Research has shown smoking has numerous adverse effects on cardiovascular and pulmonary systems in addition to its high prevalence in causing oral cancer (https:// www.cdc.gov/tobacco/data_statistics/fact_sheets/adult_data/cig_smoking/ index.htm/, accessed on December 28, 2018) [10]. Further research has exhibited smoking's relation in causing an imbalance in oral microflora, which leads to dental caries [11]. Research has indicated that nicotine increases $S$. mutans biofilm growth and the expression of several virulence factors such as antigen I/II, glucosyltransferase (GTF) and glucan-binding protein (GBP), as well as the metabolic activity of biofilm cells $[12,13]$. Its concentration in saliva of smokers ranges between $0 \mathrm{mg} / \mathrm{mL}$ to $2.27 \mathrm{mg} /$ $\mathrm{mL}[14,15]$. The CDC states that nicotine is an alkaloid that approximately represents 0.6 percent to $3 \%$ of the dry tobacco weight (https://www.cdc. gov/tobacco/data_statistics/fact_sheets/adult_data/cig_smoking/index. $\mathrm{htm} /$, accessed on December 28, 2018). The Nutrition Source report from the Harvard T. H. Chan School of Public Health states that soft drinks rank as a major source of sugar in the diets of people in the US and numerous other countries (https://www.hsph.harvard.edu/nutritionsource/healthydrinks/sugary-drinks/, accessed on June 15, 2020).

Since both the high consumption of sugar-containing soft drinks and smoking individually have been shown to increase the caries risk in individuals in various studies, more research is necessary to identify recommended soft drinks for smokers to consume in order to combat this problem $[3,4,5,11]$. This study investigated the effects of different soft drinks (regular with HFCS, sugar-free, and/or caffeine-free) with the presence of nicotine on $S$. mutans activity along with the formation of biofilm to provide accurate information to patients. The primary hypothesis to be tested here is that the addition of the sugar/HFCS-containing cola soft drinks to $S$. mutans culture in the presense of nicotine will increase bacterial growth, biofilm growth, and S. mutans metabolic activity. A second hypothesis to be examined is that the addition of caffeine-containing cola drinks to $S$. mutans cultures will inhibit biofilm formation and growth.

\section{Materials and Methods}

\section{Bacterial growth \& preparation}

In this study $S$. mutans strain UA159 was used and grown on Mitis Salivarius Sucrose Bacitracin (MSSB, Anaerobe Systems, Morgan Hill, CA, USA) agar plates. The strain was stored at $-80^{\circ} \mathrm{C}$ in tryptic soy broth (TSB, Acumedia, Baltimore, MA, USA) with $20 \%$ glycerol before use; growth condition was at 5.0 -percent carbon dioxide at $37^{\circ} \mathrm{C}$ [13]. 
Table 1 Detailed ingredients present in the various cola-flavored beverages studied ${ }^{9}$

\begin{tabular}{|c|c|c|c|}
\hline Beverage (12 oz) & Ingredients & Sugars $(\mathrm{amt} / 12 \mathrm{oz})$ & Caffeine (amt/12 oz) \\
\hline Coca-Cola Classic & $\begin{array}{l}\text { carbonated water, high fructose corn syrup, caramel color, phosphoric acid, } \\
\text { natural flavors, caffeine }\end{array}$ & $\begin{array}{c}39 \mathrm{~g} \\
0.11 \mathrm{~g} / \mathrm{mL}\end{array}$ & $\begin{array}{c}32 \mathrm{mg} \\
0.09 \mathrm{mg} / \mathrm{mL}\end{array}$ \\
\hline Diet Coke & $\begin{array}{l}\text { carbonated water, caramel color, aspartame, phosphoric acid, potassium benzoate, } \\
\text { natural flavors, citric acid, caffeine }\end{array}$ & 0 & $\begin{array}{c}42 \mathrm{mg} \\
0.12 \mathrm{mg} / \mathrm{mL}\end{array}$ \\
\hline Coca-Cola Zero Sugar & $\begin{array}{l}\text { carbonated water, caramel color, phosphoric acid, aspartame, potassium benzoate, } \\
\text { natural flavors, potassium citrate, acesulfame potassium, caffeine }\end{array}$ & 0 & $\begin{array}{c}32 \mathrm{mg} \\
0.09 \mathrm{mg} / \mathrm{mL}\end{array}$ \\
\hline Caffeine Free Coca-Cola & $\begin{array}{l}\text { carbonated water, high fructose corn syrup, caramel color, phosphoric acid, } \\
\text { natural flavors }\end{array}$ & $\begin{array}{c}39 \mathrm{~g} \\
0.11 \mathrm{~g} / \mathrm{mL}\end{array}$ & 0 \\
\hline Caffeine Free Diet Coke & $\begin{array}{l}\text { carbonated water, caramel color, aspartame, phosphoric acid, potassium benzoate, } \\
\text { natural flavors, citric acid }\end{array}$ & 0 & 0 \\
\hline $\begin{array}{l}\text { Caffeine Free } \\
\text { Coca-Cola Zero Sugar }\end{array}$ & $\begin{array}{l}\text { carbonated water, caramel color, phosphoric acid, aspartame, potassium benzoate, } \\
\text { natural flavors, potassium citrate, acesulfame potassium }\end{array}$ & 0 & 0 \\
\hline
\end{tabular}

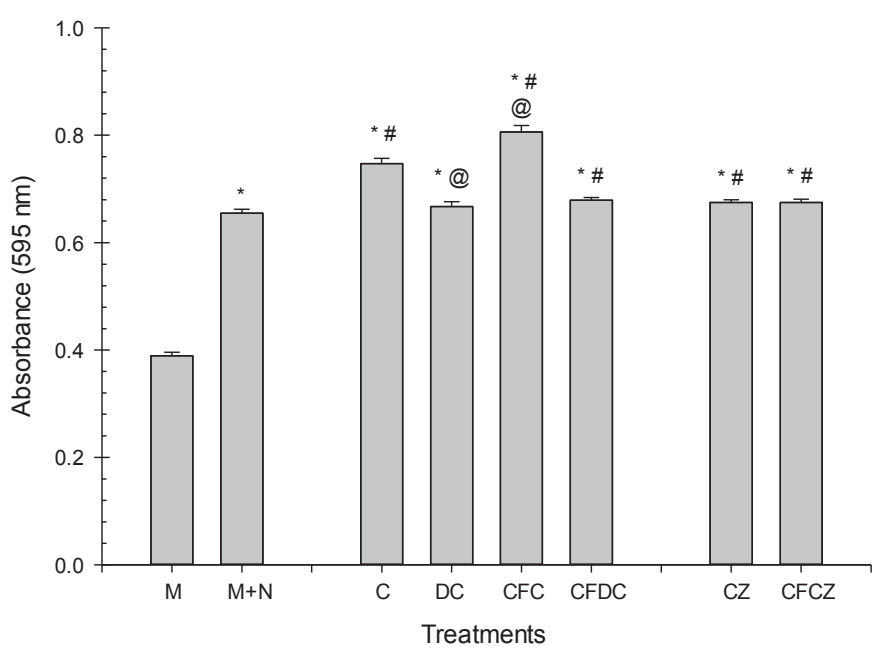

Fig. 1 Results of the effects of soft drinks and nicotine on S. mutans total growth. (M) S. mutans + TSBS, $(\mathrm{M}+\mathrm{N})$ S. mutans $+\mathrm{TSBS}+8 \mathrm{mg} / \mathrm{mL}$ nicotine, (C) S. mutans $+1: 3$ dilutions of Coca-Cola Classic in TSBS $+8 \mathrm{mg} / \mathrm{mL}$ nicotine, (DC) $S$. mutans $+1: 3$ dilutions of Diet Coke in TSBS +8 $\mathrm{mg} / \mathrm{mL}$ nicotine, (CFC) S. mutans $+1: 3$ dilutions of Caffeine free Coca-Cola Classic in TSBS +8 $\mathrm{mg} / \mathrm{mL}$ nicotine, (CFDC) S. mutans $+1: 3$ dilutions of Caffeine free Diet Coke in TSBS $+8 \mathrm{mg} / \mathrm{mL}$ nicotine, (CZ) S. mutans $+1: 3$ dilutions of Coca-Cola Zero Sugar in TSBS $+8 \mathrm{mg} / \mathrm{mL}$ nicotine, (CFCZ) S. mutans $+1: 3$ dilutions of Caffeine free Coca-Cola Zero Sugar in TSBS $+8 \mathrm{mg} / \mathrm{mL}$ nicotine. Asterisks indicate significant differences between the experimental groups compared with the control group (TSBS + S. mutans); \# indicates significant differences with S. mutans in TSBS and nicotine, @ indicates significant differences between the groups compared with Coca-Cola Classic.

\section{Effects of soft drinks on nicotine-treated $S$. mutans established biofilm}

Cola drinks used in a previous study and their detailed ingredients are shown in Table 1 [9]. The drinks were chosen according to caffeine and sugar content; three types contained caffeine, and three did not; two contained sugar, while four did not. Drinks were opened for $24 \mathrm{~h}$ to remove carbonation. TSB culture of $S$. mutans was grown overnight. The next day, $8 \mathrm{mg} / \mathrm{mL}$ of nicotine (Sigma-Aldrich Chemical Co., St. Louis, MO, USA) was diluted in tryptic soy broth supplemented with $1.0 \%$ sucrose (TSBS), then a dilution of 1:3 (based on the dilution effects of saliva on the consumed beverages) of soft drinks and nicotine-TSBS was prepared for each type of soft drink (Coca-Cola Classic, Diet Coke, Coca-Cola Zero Sugar, Caffeine-Free Coca-Cola, Caffeine-Free Diet Coke, and Caffeine-Free Coca-Cola Sugar Free, Coca-Cola Company, Atlanta, GA, USA). Next, $190 \mu \mathrm{L}$ of the $8 \mathrm{mg} / \mathrm{mL}$ of nicotine in TSBS with 1:3 dilutions of soft drinks were aliquoted into wells of a sterile 96 -well flat bottom microtiter plate. $10 \mu \mathrm{L}$ of the fresh overnight TSB culture of $S$. mutans were added to each well. The microtiter plate was incubated for $24 \mathrm{~h}$. The next day, total absorbance (biofilm and planktonic growth) was measured in a spectrophotometer (SpectraMax 190; Molecular Devices Inc., Sunnyvale, CA, USA) at $595 \mathrm{~nm}$. Later, the remaining planktonic cells were removed from the biofilm microtiter plate wells (leaving attached biofilm), and $200 \mu \mathrm{L}$ of $10 \%$ formaldehyde was added to each well for $30 \mathrm{~min}$ to fix the cells. Next, formaldehyde was removed, and the biofilm cells were washed three times with deionized water. $200 \mu \mathrm{L}$ of $0.5 \%$ crystal violet dye was added to each well and the cells were stained for $30 \mathrm{~min}$. After that, the wells were rinsed three times and $200 \mu \mathrm{L}$ of 2-isopropanol was placed into each well for $1 \mathrm{~h}$ to lyse the cells and to extract the crystal violet. Finally, the plate was read in a spectrophotometer at $490 \mathrm{~nm}$ to measure biofilm formation.

\section{Biofilm metabolic activity}

Metabolic activity of $S$. mutans biofilm was measured by a method initially described by Pierce et al. [16] for Candida albicans but adapted in a later study for $S$. mutans [13]. The method is based on biofilm cells reducing 2,3-bis(2-methoxy-4-nitro-5-sulfophenyl)-2H-tetrazolium-5-carboxanilide (XTT) to a water-soluble organic compound in the presence of menadione [13]. The same steps were followed, $200 \mu \mathrm{L}$ of XTT reagent were added and the plate was kept in the dark without $5.0 \% \mathrm{CO}_{2}$ for 2 h. Following the incubation period, the XTT reagent was transferred to another 96-well plate to detect the color change through the spectrophotometer at $490 \mathrm{~nm}$. This provides a method to compare the residual effect of an antimicrobial agent on surviving bacteria, since some agents (e.g. nicotine [17]) kill many, but not all bacteria, and the surviving microbes can remain extremely metabolically active.

\section{Statistical analysis}

Each experiment was repeated three times with each experimental set-up having $n=5$ with each set-up used 3 times resulting in $n=15$ per group. One-way ANOVA was used to compare the effects of cola exposure, presence of caffeine, nicotine and their interactions on S. mutans total growth, biofilm formation, and metabolic activity. Pair-wise comparisons were made between different groups for all three outcomes using the Sidak method. Due to non-normally distributed data (Kolmogorov-Smirnov test, " $P<0.05$ "), analyses were performed using the ranks of the data (Kolmogorov-Smirnov test, $P>0.05$, Levene's test for homogeneity of variance " $P>0.05$ "). A $5.0 \%$ significance level was used for all the tests.

\section{Results}

In general, there were considerable effects for HFCS and caffeine, in the presence of nicotine, and their interaction in all measures: total growth, biofilm formation, and metabolic activity. One-way ANOVA was used for comparison. Results are categorized in the following sections.

\section{Effects of soft drinks and nicotine on $S$. mutans total growth}

Bacterial total absorbance of each well was measured before removing the planktonic bacterial cells at $595 \mathrm{~nm}$. All groups that contained TSBS and $S$. mutans in the presence of nicotine and soft drinks exhibited a significant increase in comparison to the control group (TSBS $+S$. mutans). In addition, Caffeine-free Coca-Cola Classic demonstrated higher bacterial growth in comparison with all other types of soft drinks. However, Diet Coke demonstrated a significant decrease in total growth compared with Coca-Cola Classic (Fig. 1). 


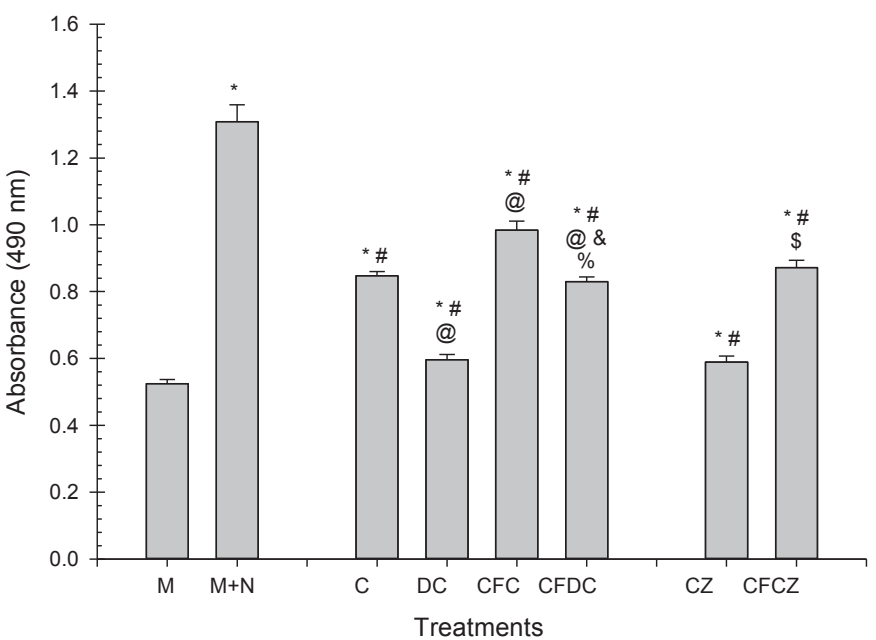

Fig. 2 Results of the effects of soft drinks and nicotine on $S$. mutans biofilm formation. (M) $S$ mutans + TSBS, $(\mathrm{M}+\mathrm{N})$ S. mutans $+\mathrm{TSBS}+8 \mathrm{mg} / \mathrm{mL}$ nicotine, (C) $S$. mutans $+1: 3$ dilutions of Coca-Cola Classic in TSBS $+8 \mathrm{mg} / \mathrm{mL}$ nicotine, (DC) S. mutans $+1: 3$ dilutions of Diet Coke in TSBS $+8 \mathrm{mg} / \mathrm{mL}$ nicotine, (CFC) S. mutans $+1: 3$ dilutions of Caffeine free Coca-Cola Classic in TSBS $+8 \mathrm{mg} / \mathrm{mL}$ nicotine, (CFDC) $S$. mutans +1.3 dilutions of Caffeine free Diet Coke in TSBS $+8 \mathrm{mg} / \mathrm{mL}$ nicotine, (CZ) S. mutans $+1: 3$ dilutions of Coca-Cola Zero Sugar in TSBS + $8 \mathrm{mg} /$ $\mathrm{mL}$ nicotine, (CFCZ) S. mutans $+1: 3$ dilutions of Caffeine free Coca-Cola Zero Sugar in TSBS + $8 \mathrm{mg} / \mathrm{mL}$ nicotine. Asterisks indicate significant differences between the experimental groups and the control group (S. mutans + TSBS); \# indicate significant differences between the groups and the S. mutans with TSBS and nicotine; @ indicates significant differences compared with Coca-Cola Classic, and symbol (\&) indicates significant differences compared with Diet Coke, and $\$$ indicates significant differences compared with Coca-Cola Zero Sugar; and \% indicates significant differences compared with caffeine free Coca-Cola Classic.

\section{Effects of soft drinks and nicotine on $\boldsymbol{S}$. mutans biofilm formation}

The results of the experimental groups in the crystal violet assay demonstrated a significant enhancement of the biofilm formation in all groups compared with the negative bacterial control. The presence of nicotine formed the highest biofilm in contrast with other groups that included soft drinks. When comparing specific beverages, Diet Coke formed less biofilm compared with Coca-Cola Classic. In terms of caffeine and biofilm formation, Caffeine-Free Coke displayed a significant increase in biofilm formation in comparison with Coca-Cola Classic, Diet Coke, and CaffeineFree Diet Coke (Fig. 2).

\section{Effects of soft drinks and nicotine on $\boldsymbol{S}$. mutans metabolic activity}

The metabolic activity of $S$. mutans without nicotine or soft drinks was clearly lower than the metabolic activity of $S$. mutans in the presence of soft drinks and nicotine. The caffeinated soft drinks were more metabolically active in comparison with their paired caffeine-free sodas. In terms of HFCS and S. mutans metabolic activity, Diet Coke and Coca-Cola Zero Sugar were less active than Coca-Cola Classic (Fig. 3).

\section{Discussion}

Numerous studies have investigated the correlation between smoking and caries risk, and all concluded that nicotine enhances $S$. mutans biofilm formation and biofilm metabolic activity $[11,12,18]$. Furthermore, results from a study carried out by Huang et al. suggested that smoking can raise caries progression through promoting $S$. mutans biofilm formation on the tooth surface [13]. S. mutans is a normal flora species in the oral cavity, and research has shown it becomes harmful under certain conditions in the presence of fermentable carbohydrates [19-21]. Previous studies have demonstrated the effects of sweetened drinks, particularly soda, on caries risk and its progression [22-24]. Although soft drink consumption is widespread across the US, there is a lack of evidence regarding its direct effects in the presence of nicotine on $S$. mutans biofilm formation and metabolic activity. This study explored the impact of different soft drinks (regular with HFCS, sugar-free, and caffeine-free) in the presence of nicotine on $S$. mutans activity on the formation of biofilm for potential recommendations for disease prevention and patient education.

Past in vitro and more in-vivo research defined the amount of nicotine present in saliva and the amount absorbed into biofilm [14]. This study

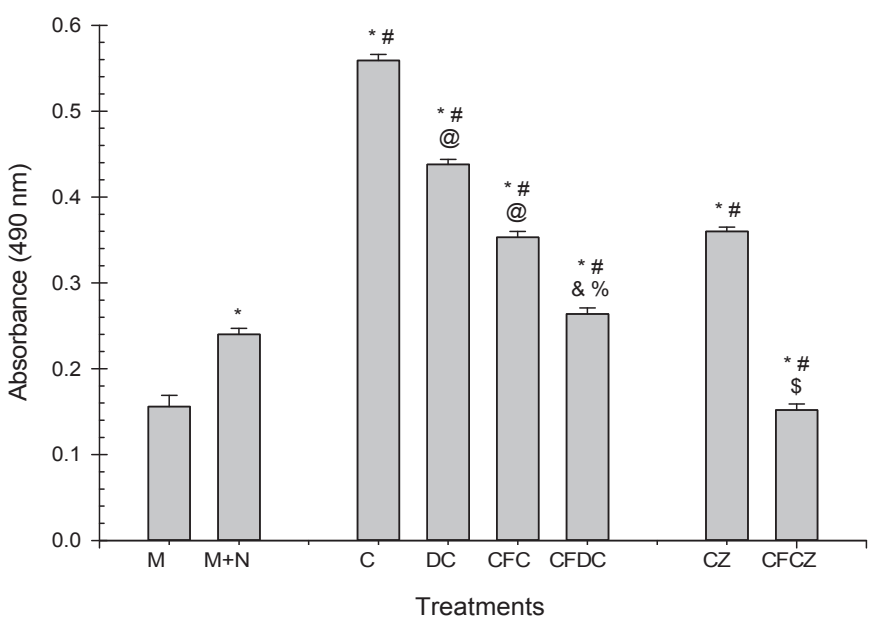

Fig. 3 Results of the effects of soft drinks and nicotine on $S$. mutans metabolic activity. (M) $S$. mutans + TSBS, (M+N) S. mutans + TSBS $+8 \mathrm{mg} / \mathrm{mL}$ nicotine, (C) S. mutans $+1: 3$ dilutions of Coca-Cola Classic in TSBS $+8 \mathrm{mg} / \mathrm{mL}$ nicotine, (DC) $S$. mutans $+1: 3$ dilutions of Diet Coke in TSBS $+8 \mathrm{mg} / \mathrm{mL}$ nicotine, (CFC) S. mutans $+1: 3$ dilutions of Caffeine free Coca-Cola Classic in TSBS $+8 \mathrm{mg} / \mathrm{mL}$ nicotine, (CFDC) S. mutans $+1: 3$ dilutions of Caffeine free Diet Coke in TSBS $+8 \mathrm{mg} / \mathrm{mL}$ nicotine, (CZ) S. mutans $+1: 3$ dilutions of Coca-Cola Zero Sugar in TSBS $+8 \mathrm{mg}$ / $\mathrm{mL}$ nicotine, (CFCZ) S. mutans $+1: 3$ dilutions of Caffeine free Coca-Cola Zero Sugar in TSBS + $8 \mathrm{mg} / \mathrm{mL}$ nicotine. Asterisks indicate significant differences between the experimental groups and the control group (S. mutans + TSBS), \# indicate significant differences between the groups and the S. mutans with TSBS and nicotine; @ indicates significant difference compared with Coca-Cola Classic, and symbol (\&) indicates significant differences compared with Diet Coke, and \$ indicates significant differences compared with Coca-Cola Zero Sugar.

measured the amount of nicotine present in smokers' and non-smokers' saliva and revealed that light-to-medium smokers' saliva contained $0.0 \mathrm{mg} /$ $\mathrm{mL}$ to $1.33 \mathrm{mg} / \mathrm{mL}$ of nicotine while heavy smokers' saliva had $0.0 \mathrm{mg} /$ $\mathrm{mL}$ to $2.27 \mathrm{mg} / \mathrm{mL}$ [14]. Assuming that $1 \mathrm{mg} / \mathrm{mL}$ of nicotine is present in human saliva, the caffeine concentration in soft drinks should be significant in inhibiting the formation of S. mutans.

The main hypothesis of this study was supported by the findings that showed the addition of sugar-containing cola-flavored products to $S$. mutans cultures in the presence of nicotine will increase bacterial biofilm growth, increase $S$. mutans metabolic activity; therefore, the null hypothesis for the main hypothesis was rejected. The results also showed marked inhibition of the biofilm formation and growth of the $S$. mutans with the addition of caffeinated soft drinks, although the null hypothesis for this secondary hypothesis was not rejected. These outcomes demonstrated that HFCS increases both biofilm formation and metabolic activity, which supports previous findings that the presence of fermentable carbohydrates will elevate caries activity $[9,25,26]$. Caffeine's effect on biofilm formation was not significantly greater than the control group, however, its effect was clearly noticeable on metabolic activity. In both biofilm growth and metabolism, caffeine plays a role in increasing their rates, even though it is not as impactful as the role of HFCS. In each case, the results do not negate the hypothesis that caffeine has an inhibitory effect. The findings in this study suggest that smokers should choose caffeinated sugar-free soda drinks in order to decrease their potential for developing caries. Several limitations were found in this study and and can be summarized by noting: 1) a single strain of $S$. mutans was used where other strains could have different effects; 2) the study lacked a multi-species model; 3) the experiment lacked salivary components; and 4) the study used a fixed nicotine concentration.

In conclusion, sugar-free caffeinated soft drinks showed significant effects in inhibiting $S$. mutans biofilm formation, as well as metabolic activity in the presence of nicotine. On the other hand, nicotine-induced $S$. mutans demonstrated increased biofilm formation and metabolic activity in the presence of HFCS and caffeine in soft drinks. Therefore, smokers with a high consumption of soft drinks should consider shifting to sugar-free and caffeinated versions in order to minimize the chance of developing dental caries by reducing biofilm formation. Future research should be carried out to support the results of this study and further examine the long-term outcomes for smokers and their choice of colas, concentrating 
on the effects of addition and/or absence of sugar and caffeine in various combinations, to reduce $S$. mutans biofilm formation.

\section{Acknowledgments}

The authors would like to thank the Oral Health Research Institute, Indiana University School of Dentistry, the IUSD Cariology, Operative Dentistry, and Public Health Dentistry Department, in particular the Graduate Operative and Cariology Program, and all associated laboratories and facilities utilized in this study for their support as well as the experts involved.

\section{Conflict of interest}

The authors declare no conflict of interest.

\section{References}

1. Loesche WJ (1986) Role of Streptococcus mutans in human dental decay. Microbiol Rev 50, 353-380.

2. Ismail AI, Burt BA, Eklund SA (1984) The cariogenicity of soft drinks in the United States. J Am Dent Assoc 109, 241-245.

3. French SA, Lin BH, Guthrie JF (2003) National trends in soft drink consumption among children and adolescents age 6 to 17 years: prevalence, amounts, and sources, 1977/1978 to 1994/1998. J Am Diet Assoc 103, 1326-1331.

4. Leme AP, Koo H, Bellato C, Bedi G, Cury J (2006) The role of sucrose in cariogenic dental biofilm formation -- new insight. J Dent Res 85, 878-887.

5. Duffey KJ, Popkin BM (2008) High-fructose corn syrup: is this what's for dinner? Am J Clin Nutr 88, 1722s-1732s.

6. James JE (1994) Caffeine, health and commercial interests. Addiction 89, 1595-1599.

7. Ferrazzano GF, Amato I, Ingenito A, De Natale A, Pollio A (2009) Anti-cariogenic effects of polyphenols from plant stimulant beverages (cocoa, coffee, tea). Fitoterapia 80, 255262.

8. Ruenis AP, Rosalen PL, Volpato MC, Groppo FC (2000) Effects of caffeine and theophylline on the development of dental caries in rats. Biol Pharm Bull 23, 339-343.

9. Dotsey RP, Moser EAS, Eckert GJ, Gregory RL (2017) Effects of cola-flavored beverages and caffeine on Streptococcus mutans biofilm formation and metabolic activity. J Clin Pediatr Dent 41, 294-299.
10. Gandini S, Botteri E, Iodice S, Boniol M, Lowenfels AB, Maisonneuve P et al. (2008) Tobacco smoking and cancer: a meta-analysis. Int J Cancer 122, 155-164.

11. Li M, Huang R, Zhou X, Qui W, Xu X, Gregory RL (2016) Effect of nicotine on cariogenic virulence of Streptococcus mutans. Folia Microbiol (Praha) 61, 505-512.

12. Zonuz AT, Rahmati A, Mortazavi H, Khashabi E, Farahani RM (2008) Effect of cigarette smoke exposure on the growth of Streptococcus mutans and Streptococcus sanguis: an in vitro study. Nicotine Tob Res 10, 63-67.

13. Huang R, Li M, Gregory RL (2012) Effect of nicotine on growth and metabolism of Streptococcus mutans. Eur J Oral Sci 120, 319-325.

14. Feyerabend C, Higenbottam T, Russell M (1982) Nicotine concentrations in urine and saliva of smokers and non-smokers. Br Med J (Clin Res Ed) 284, 1002-1004.

15. Dhar $P$ (2004) Measuring tobacco smoke exposure: quantifying nicotine/cotinine concentration in biological samples by colorimetry, chromatography and immunoassay methods. J Pharm Biomed Anal 35, 155-168.

16. Pierce CG, Uppuluri P, Tristan AR, Wormley, FL Jr., Mowat E, Ramage G et al. (2008) A simple and reproducible 96-well plate-based method for the formation of fungal biofilms and its application to antifungal susceptibility testing. Nat Protoc 3, 1494-1500.

17. Lee J, Taneja V, Vassallo R (2012) Cigarette smoking and inflammation: cellular and molecular mechanisms. J Dent Res 91, 142-149.

18. Liu S, Wu T, Zhou X, Zhang B, Huo S, Yang Y et al. (2018) Nicotine is a risk factor for dental caries: an in vivo study. J Dent Sci 13, 30-36.

19. Bratthall D (1991) Mutans streptococci -dental, oral and global aspects. J Indian Soc Pedod Prev Dent 9, 4-12.

20. Aas JA, Paster BJ, Stokes LN, Olsen I, Dewhirst FE (2005) Defining the normal bacterial flora of the oral cavity. J Clin Microbiol 43, 5721-5732.

21. Forssten SD, Bjorklund M, Ouwehand AC (2010) Streptococcus mutans, caries and simulation models. Nutrients 2, 290-298.

22. Heller KE, Burt BA, Eklund SA (2001) Sugared soda consumption and dental caries in the United States. J Dent Res 80, 1949-1953.

23. Marshall TA, Levy SM, Broffitt B, Warren, JJ, Eichenberger-Gilmore JM, Burns, TL et al. (2003) Dental caries and beverage consumption in young children. Pediatrics 112, e184e191.

24. Bowen WH, Lawrence RA (2005) Comparison of the cariogenicity of cola, honey, cow milk, human milk, and sucrose. Pediatrics 116, 921-926.

25. Bray GA, Nielsen SJ, Popkin BM (2004) Consumption of high-fructose corn syrup in beverages may play a role in the epidemic of obesity. Am J Clin Nutr 79, 537-543.

26. Lim S, Sohn W, Burt BA, Sandretto AM, Kolker JL, Marshall TA et al. (2008) Cariogenicity of soft drinks, milk and fruit juice in low-income african-american children: a longitudinal study. J Am Dent Assoc 139, 959-967; quiz 95. 